\title{
Análises energéticas e econômicas de sistemas motrizes de uma empresa de processamento de materiais ferromagnéticos, em Itabira-MG
}

\author{
Energy and economic analysis of motor systems of a ferromagnetic materials processing company,
} in Itabira-MG

Análisis energético y económico de sistemas motores de una empresa procesadora de materiales ferromagnéticos, en Itabira-MG

Cauê Mello Cavalher Fernandes ORCID: https://orcid.org/0000-0003-3531-6411 Universidade Federal de Itajubá, Brasil E-mail: cauecavalher@gmail.com

Rafael Balbino Cardoso

ORCID: https://orcid.org/0000-0003-4239-3108 Universidade Federal de Itajubá, Brasil E-mail: cardosorb@unifei.edu.br

\begin{abstract}
Resumo
O presente estudo avalia as possibilidades de trocas de sistemas motrizes menos eficientes por mais eficientes, através de um projeto de eficiência energética destinada a uma empresa de processamento de materiais ferromagnéticos, situada no município de Itabira - MG. O artigo mostra a influência de diversas variáveis na operação da planta motriz, realizando análises de grande parte do processo produtivo da empresa e propondo a substituição de parte do antigo maquinário da empresa por maquinários mais moderno e mais eficiente, levando a significativas economias no consumo de energia, bem como boas atratividades econômicas.
\end{abstract}

Palavras-chave: Eficiência energética; Viabilidade econômica; Máquinas motrizes.

\begin{abstract}
This study evaluates the possibilities of changing less efficient drive systems for more efficient ones, through an energy efficiency project for a ferromagnetic material processing company, located in the municipality of Itabira MG. The article shows the influence of several variables on the operation of the power plant, analyzing a large part of the company's production process and proposing the replacement of part of the company's old machinery by more modern and more efficient machinery, leading to significant savings in the consumption of energy as well as good economic attractiveness.
\end{abstract}

Keywords: Energy efficiency; Economic feasibility; Motor machines.

\section{Resumen}

Este estudio evalúa las posibilidades de cambiar sistemas de propulsión menos eficientes por otros más eficientes, a través de un proyecto de eficiencia energética para una empresa procesadora de materiales ferromagnéticos, ubicada en el municipio de Itabira - MG. El artículo muestra la influencia de diversas variables en el funcionamiento de la central, analizando gran parte del proceso productivo de la empresa y proponiendo la sustitución de parte de la maquinaria antigua de la empresa por maquinaria más moderna y eficiente, lo que supone un importante ahorro en la producción. consumo de energía y buen atractivo económico.

Palabras clave: Eficiencia energética; Viabilidad económica; Máquinas motrices.

\section{Introdução}

$\mathrm{O}$ assunto sobre eficiência energética no uso final da energia vem ganhando destaque a partir do momento em que as demandas energéticas dos centros urbanos e industriais se tornaram excessivamente altas e originaram um obstáculo para os países que buscam o desenvolvimento e suprir suas demandas energéticas (Fonseca, et al., 2018). Diante deste contexto, empresas e os órgãos governamentais passaram a fazer investimentos em pesquisas e projetos de eficiência energética, de modo a reduzir seu gasto com expansão da matriz energética e obter um melhor aproveitamento da energia motriz na produção 
de bens de consumo nas indústrias.

Devido as crescentes demandas por energia no país, surge a necessidade de promoção das conversões energéticas de forma mais eficiente em todos os setores produtivos da sociedade. Essa promoção está associada a fatores econômicos e, muitas vezes os investimentos para a promoção da eficiência energética no uso final é mais barato que investimentos na ampliação da matriz energética (Cardoso, 2015).

Para o Ministério das Minas e Energia (Brasil, 2007), a melhoria da eficiência energética resulta em economia de energia por meio de redução de perdas de energia, sem prejuízo da atividade realizada, podendo ser conseguida pelo uso de equipamentos mais eficientes ou pelo uso racional da energia ou, ainda, pela substituição de uma fonte energética. Para o World Energy Council (2010), a melhoria da eficiência energética pode ser conseguida tanto por meio de mudança tecnológica quanto por meio de gestão organizacional ou mudança comportamental (Sola \& Mota, 2015).

Aproximadamente $65 \%$ da eletricidade consumida pela indústria é usada por sistemas motorizados (De Keulenaer et al. 2004; Xenergy 1998). A eficiência dos sistemas acionados por motores pode ser aumentada reduzindo as perdas nos enrolamentos do motor, usando melhor aço magnético, melhorando a aerodinâmica do motor e melhorando as tolerâncias de fabricação. No entanto, maximizar a eficiência requer o dimensionamento adequado de todos os componentes, melhorando a eficiência dos dispositivos de uso final (bombas, ventiladores, etc.), reduzindo as perdas de transmissão elétrica e mecânica e o uso de procedimentos de operação e manutenção adequados (Worrel et al. 2009).

O investimento em eficiência energética traz resultados significativos não somente à empresa, mas de forma global. Segundo Bortoni, et al. (2013), a introdução de motores energicamente eficientes no mercado brasileiro levaram a uma economia de energia de cerca de $493 \mathrm{GW}$ h e uma redução na demanda de pico de $150 \mathrm{MW}$ em 2012, sendo que a maior parte da economia de energia, cerca de $91 \%$ do total, está relacionada à motores rotulados padrão.

Neste artigo, a eficiência energética é tratada no âmbito da mudança tecnológica, ou seja, substituição de maquinário motriz antigo e mal dimensionado, por um mais robusto, econômico (de alto rendimento) e devidamente projetado para a carga com a qual irá operar; projeto este realizado em uma empresa de processamento de materiais ferromagnéticos, no município de Itabira-MG.

\section{Motores de Indução Trifásicos}

Este capítulo apresenta algumas das principais características de motores de indução trifásicos, já que estes equipamentos são os maiores consumidores de energia elétrica do país e possuem alta representatividade no consumo de energia na empresa estudada.

Devido à sua robustez e simplicidade, os motores de indução trifásicos são amplamente utilizados nas indústrias, partindo de motores fracionários até os de grande porte, sendo o motor de indução do tipo rotor de gaiola o mais utilizado, demonstrado na Figura 1. 
Figura 1: Composição de um motor de indução trifásico.

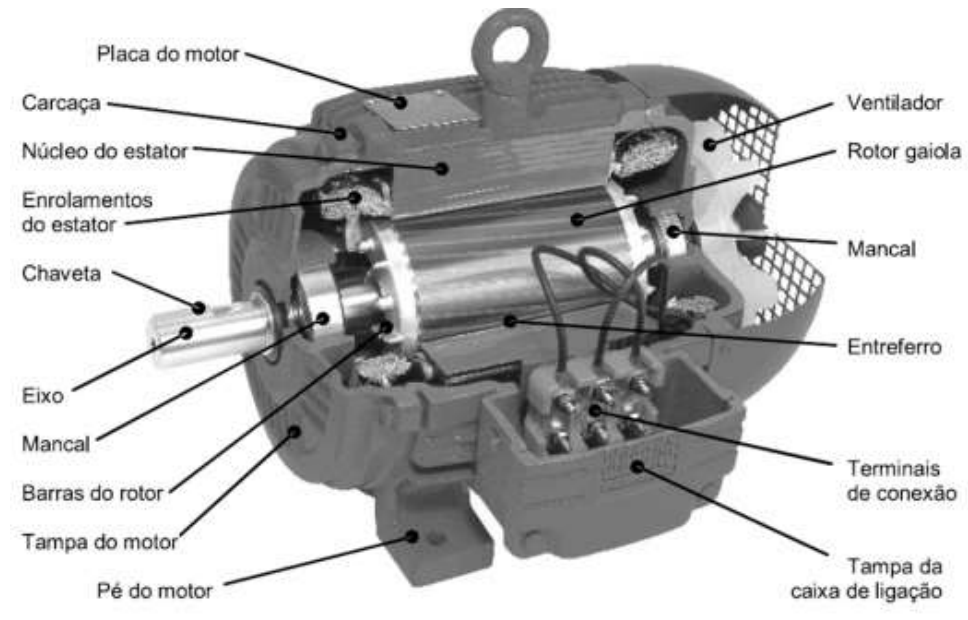

Fonte: Cardoso, et al. (2009).

O princípio de operação do motor de indução consiste na transformação da energia elétrica em mecânica, através de fenômenos eletromagnéticos. Durante esse processo, a conversão não é completa devido a uma série de perdas que ocorrem no interior da máquina, tais como perda Joule no estator e no rotor, perdas no ferro tais como Histerese e Foucault, além de perdas por dispersão e perdas por atrito e ventilação.

O motor de indução é uma máquina intrinsicamente eficiente. O formato da sua curva de rendimento revela um largo patamar que cobre uma faixa de 50\% até 100\% de carga com altos rendimentos. Tal comportamento não é encontrado em outras concepções de máquinas, tais como as hidráulicas ou as térmicas, onde o rendimento cai rapidamente quando se opera fora das condições nominais (Santos, et al. 2007).

Os motores de indução possuem uma particularidade que deve ser levada em consideração quando operam em ambiente industrial de médio e grande porte, o seu fator de carregamento. A curva de carga oscila com a potência demandada da máquina, e para baixo fator de carregamento, a eficiência da máquina é afetada. Esta perda de eficiência e o baixo fator de carregamento ocorrem quando a máquina opera abaixo de seus valores nominais. As Figuras 2 e 3 mostram a curva de carga de duas máquinas distintas (uma de $1 \mathrm{CV}$ e outra de $550 \mathrm{CV}$, obtidas a partir do site da fabricante WEG), sendo o foco de análise a curva em azul claro, que representa o rendimento da máquina em função da potência fornecida com relação à potência nominal. 
Research, Society and Development, v. 11, n. 2, e0211224878, 2022

(CC BY 4.0) | ISSN 2525-3409 | DOI: http://dx.doi.org/10.33448/rsd-v11i2.24878

Figura 2: Curva de carga de uma máquina de $1 \mathrm{HP}$.

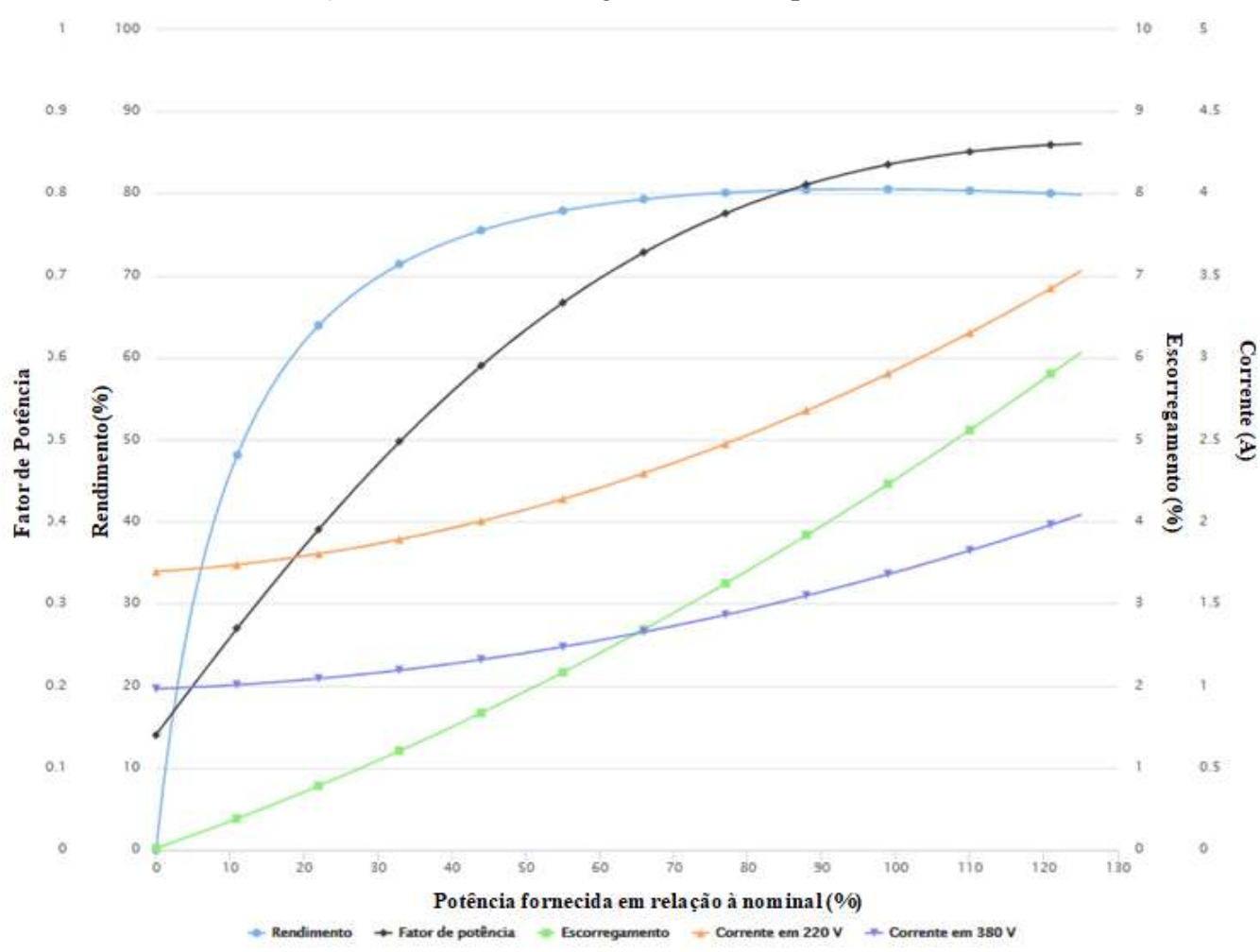

Fonte: Cardoso, et al. (2009).

Através da curva de carga, nota-se que o rendimento da máquina oscila com a porcentagem da potência fornecida em relação à nominal, fator este denominado de carregamento. Em geral, os motores de indução trifásicos encontram seu ponto ótimo de carregamento entre 75 a $90 \%$ da potência nominal.

A Figura 3 mostra a curva de carga para um motor de $900 \mathrm{CV}$, sendo possível a partir dela, perceber a diferença entre as curvas de carga entre motores de alta e baixa potência. 
Figura 3: Curva de carga de uma máquina de 550 HP.

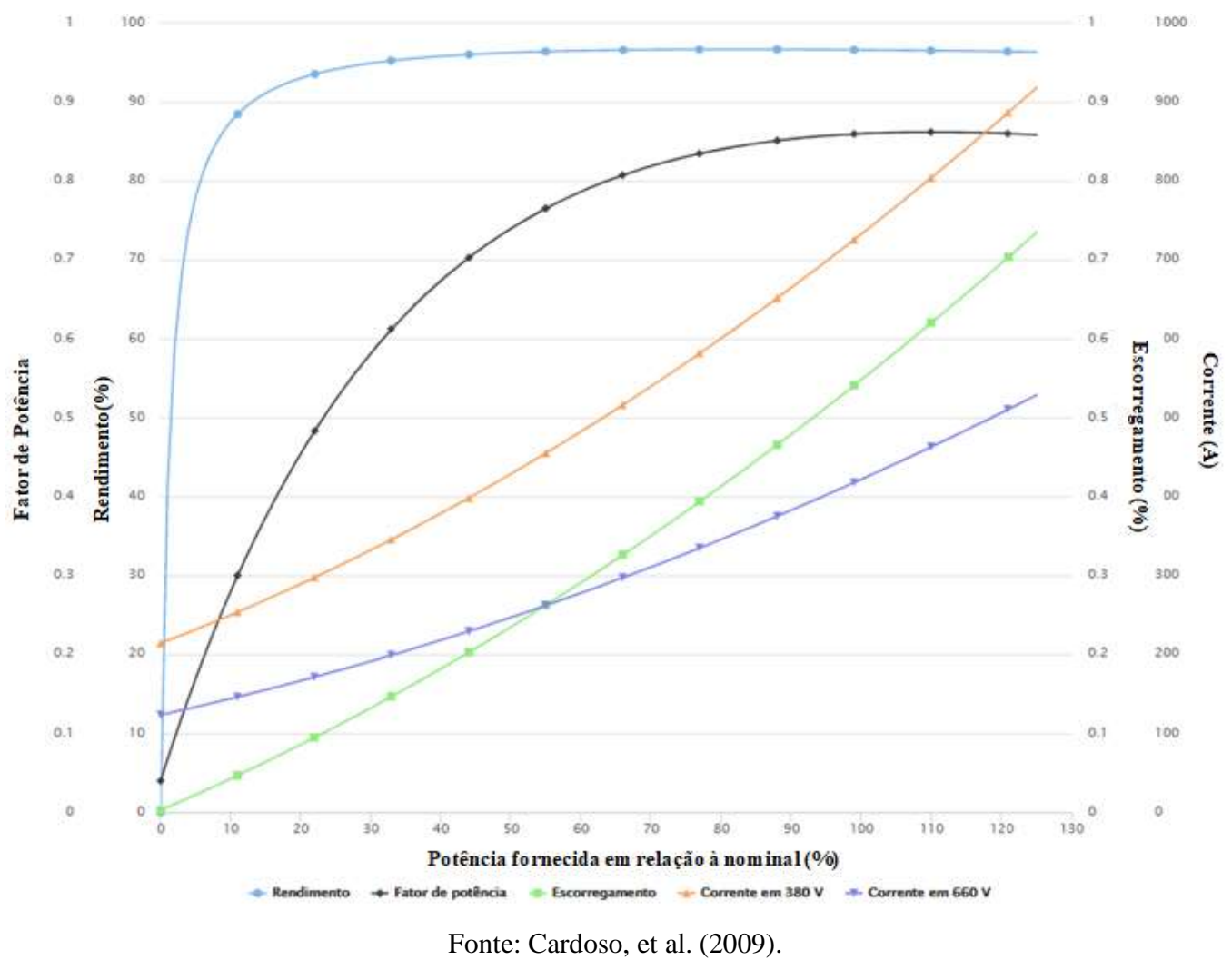

Como pode ser observada, a curva de carga é diferente para cada máquina, assim como a queda de eficiência, em função da potência fornecida em relação à nominal. A distribuição das perdas em um motor varia de acordo com seu carregamento. Fora das condições nominais, a distribuição percentual das perdas é totalmente diferente e seus valores absolutos variam significativamente. Embora os valores percentuais das perdas variem ao longo da condição de carga, a soma das parcelas das perdas por histerese e Foucault, atrito e ventilação, e adicionais, permanecem constante, enquanto que as perdas Joule no estator e rotor, variam com o quadrado do carregamento (Nogueira, et al. 2015).

A distribuição das perdas também oscila com a faixa de potência da máquina, como pode ser notado nas Figuras $2 \mathrm{e}$ 3,ou seja, uma máquina de maior potência tem uma menor sensibilidade na sua curva de eficiência, de forma que caso seu carregamento seja baixo, o seu rendimento não é drasticamente afetado. Entretanto, por se tratar de um motor com alta potência, qualquer perda de rendimento ocasiona altas perdas energéticas.

Apesar de os motores de indução apresentarem uma boa eficiência, segundo Moreira, et al. (2007), o motivo de possuírem um grande potencial de economia de energia se baseia em dois fatores. O primeiro é a grande quantidade de unidades instaladas. Os motores de indução são responsáveis pelo consumo de aproximadamente $25 \%$ de toda energia elétrica gerada no Brasil. O segundo fator é a má aplicação de um grande percentual das unidades instaladas. Problemas de acoplamento mecânico, limpeza e lubrificação e acima de tudo, mau dimensionamento, são exemplos de más aplicações, as quais contribuem com redução de todo sistema motor-carga.

\section{Caracterização da Empresa em Estudo}

A seguir são apresentadas algumas das principais características da empresa estudada, de processamento de materiais ferromagnéticos. 


\section{a) Máquinas de Alto Rendimento}

Os motores de alto rendimento se apresentam como boa alternativa para a economia de energia em sistemas motrizes. Eles são fabricados de modo a terem menores perdas em seu sistema, como por exemplo, o aumento da quantidade de cobre nos enrolamentos do motor de modo a ter menores perdas Joule. Consequentemente são mais caros que os motores normais, porém sua economia de energia em longo prazo compensa o investimento. A maior parte dos equipamentos consumidores de energia da empresa em estudo é composta por máquinas motrizes.

\section{b) Mercado Livre de Energia}

A empresa em questão, está situada na modalidade tarifária do mercado livre de energia, mais precisamente na modalidade TUSD Livre A4 Verde, com atendimento em tensão superior a 2,3 kV, que corresponde a uma tarifa mais barata de energia, porém, incluso também o pagamento da utilização das linhas de transmissão, energia ativa e reativa por demanda, horário de ponta e horário fora de ponta.

\section{c) Condicionamento Ambiental}

A empresa utiliza basicamente equipamentos de condicionamento do tipo janela e split, totalizando aproximadamente 40 mil Watts de potência instalada. Através de uma análise dos setores produtivos e administrativos da empresa, e levando em consideração que os setores são separados e distantes um dos outros, não se torna viável a instalação de uma central de condicionamento única na empresa.

\section{d) Sistema de Iluminação}

A empresa em questão possui 18 setores com iluminação instalada e um gasto mensal de aproximadamente R\$ 2.000,00 em energia destinada à iluminação. A maior parte de suas instalações conta com lâmpadas e luminárias fluorescentes, LED e vapor de sódio, e, portanto, não justifica um investimento para melhorias neste quesito, visto que os resultados seriam insignificantes comparados ao consumo energético total da empresa.

Logo, o foco deste estudo está nas plantas motrizes de dois galpões produtivos da empresa.

\section{e) Processo Produtivo da Empresa}

O primeiro passo para começar a elaborar um plano de eficiência energética industrial é entender o processo produtivo da empresa, desde a matéria bruta até o produto final. É necessário compreender a complexidade do maquinário da empresa e sua contribuição com os custos de energia, assim como a sua condição de operação, levando em conta fatores como o carregamento das máquinas de indução, corrente consumida e potência dos motores.

A empresa analisada neste estudo atua no setor de ferritas e mantas magnéticas, e possui um total de 1.912,7 kW de potência de maquinário instalada. Analisaremos então, neste artigo o galpão responsável pela produção de Manta Magnética e Compound, responsável por $44 \%$ da potência instalada, assim como galpão de Ferrita, que representa 38,5\% da carga total da empresa, totalizando $82,5 \%$ da potência elétrica disponível na companhia.

No processo produtivo da Manta Magnética, destacam-se a utilização de britadores, misturadores e extrusores como principais sistemas motrizes, além de seus subsistemas e equipamentos adjacentes, responsáveis pelo produto final. Os fornos são movidos a combustíveis fósseis e, portanto, não são relevantes para a análise de eficiência energética neste artigo em específico.

No Galpão de Ferrita, o processo produtivo se dá principalmente através dos misturadores, agitadores, britadores e moinhos, máquinas robustas que operam com uma carga elevada. A partir da definição do entendimento do processo produtivo 
da empresa e dos equipamentos mais utilizados e, portanto, vitais para o processo, cria-se a base para o estudo de eficiência energética.

\section{f) Consumo Energético dos Galpões Analisados}

O galpão produtivo de manta/compound é o maior responsável pelo consumo de energia da empresa, com aproximadamente 40 componentes e máquinas responsáveis por um consumo total de 844,81 kW. Deste galpão, serão analisados 13 motores de indução, responsáveis por $85,94 \%$ do seu consumo elétrico.

A seguir se encontra a Tabela 1, referente ao tempo de operação das máquinas a serem analisadas no galpão de manta/compound, durante o período de 1 ano, dados arquivados pela empresa durante o período de 10/01/2018 a 08/01/2019. Estes dados serão importantes para a base dos cálculos da economia com energia, a ser obtida após a substituição dos motores trifásicos antigos da empresa por outros mais eficientes e dimensionados corretamente para seu uso.

O galpão de ferrita é o segundo galpão produtivo que mais consome da rede, com o total de 65 componentes e máquinas responsáveis por uma potência instalada total de 736,85 kW. Serão analisadas 20 máquinas/componentes que representam $83,72 \%$ da potência instalada deste galpão.

Tabela 1: Máquinas do Galpão de Produção de Manta Magnética e Compound.

\begin{tabular}{|c|c|c|c|}
\hline & & HRS. & $\begin{array}{c}\text { TRABALHADAS } \\
\text { (2018) }\end{array}$ \\
\hline EQUIPAMENTO & CV & KW & 279 \\
\hline MÁQUINA 1 & 100 & 75 & 290 \\
\hline MÁQUINA 2 & 100 & 75 & 623 \\
\hline MÁQUINA 3 & 100 & 75 & 385 \\
\hline MÁQUINA 4 & 40 & 30 & 279 \\
\hline MÁQUINA 5 & 20 & 15 & 2.844 \\
\hline MÁQUINA 6 & 75 & 56 & 4.758 \\
\hline MÁQUINA 7 & 300 & 225 & 906 \\
\hline MÁQUINA 8 & 20 & 17 & 1.122 \\
\hline MÁQUINA 9 & 20 & 15 & 1.896 \\
\hline MÁQUINA 10 & 20 & 15 & 24 \\
\hline MÁQUINA 11 & 20 & 15 & 289 \\
\hline MÁQUINA 12 & 50 & 37 & 4.191 \\
\hline MÁQUINA 13 & 75 & 55 & \\
\hline
\end{tabular}

Fonte: Autores.

Os tempos de operação anuais das máquinas de indução pertencentes ao galpão de ferrita seguem informados na Tabela 2 a seguir. 
Tabela 2: Máquinas do Galpão de Produção de Ferrita.

\begin{tabular}{|c|c|c|c|}
\hline EQUIPAMENTO & CV & $\mathbf{K W}$ & $\begin{array}{c}\text { HRS. } \\
\text { TRABALHADAS } \\
(\mathbf{2 0 1 8 )}\end{array}$ \\
\hline MÁQUINA 14 & 5 & 3,75 & 4.293 \\
\hline MÁQUINA 15 & 7,5 & 5,62 & 4.502 \\
\hline MÁQUINA 16 & 5 & 3,75 & 4.167 \\
\hline MÁQUINA 17 & 5 & 3,75 & 4.764 \\
\hline MÁQUINA 18 & 5 & 3,75 & 4.440 \\
\hline MÁQUINA 19 & 50 & 37,5 & 349 \\
\hline MÁQUINA 20 & 30 & 22,5 & 2.533 \\
\hline MÁQUINA 21 & 30 & 22,5 & 2.347 \\
\hline MÁQUINA 22 & 30 & 22,5 & 652 \\
\hline MÁQUINA 23 & 40 & 30 & 2.533 \\
\hline MÁQUINA 24 & 40 & 30 & 2.347 \\
\hline MÁQUINA 25 & 30 & 22,5 & 652 \\
\hline MÁQUINA 26 & 40 & 30 & 2.162 \\
\hline MÁQUINA 27 & 100 & 75 & 1.197 \\
\hline MÁQUINA 28 & 100 & 75 & 1.144 \\
\hline MÁQUINA 29 & 150 & 112,5 & 947 \\
\hline MÁQUINA 30 & 20 & 15 & 26 \\
\hline MÁQUINA 31 & 5 & 3,75 & 399 \\
\hline MÁQUINA 32 & 20 & 15 & 329 \\
\hline MÁQUINA 33 & 30 & 22,5 & 14 \\
\hline
\end{tabular}

Fonte: Autores.

\section{Metodologia}

A metodologia aplicada a este projeto indica ações necessárias para as implementações das medidas de eficientização energética em motores de indução, sendo divididas em quatro etapas, e seguindo os modelos de equações definidas em Santos et al., como descritas a seguir.

Etapa 1: Análise dos dados e definição dos motores potencialmente ineficientes. Obtidos os dados de placa dos motores, foram determinados os casos potenciais em função do carregamento.Para isso, foi utilizada a equação (1) para cálculo do carregamento (FC) em regime permanente:

\section{Equação (1):}

$$
F C=\frac{2 \times(\mathrm{It}-\mathrm{Io})}{2 \times(\mathrm{In}-\mathrm{Io})}
$$

Nesta expressão,

It: É a corrente em carga medida, ou corrente de trabalho (A);

In: Corrente nominal de placa do motor $(\mathrm{A})$;

Io: Corrente a vazio (A).

Quanto a corrente a vazio (Io), caso não seja possível medir seu valor, pois muitas vezes não é simples ou viável cessar temporariamente uma operação no setor industrial para obter este valor, então existe uma equação com a qual se pode 
obter um valor aproximado, como demonstrado na equação (2).

$$
\begin{gathered}
\text { Equação (2): } \\
I o=\frac{(56,93+14,53 \times \mathrm{LN}(\mathrm{p}))-(7,23 \times \mathrm{LN}(\mathrm{Pn}))}{100} x I n
\end{gathered}
$$

Onde,

$\mathrm{p}$ = número de pólos da máquina de indução trifásica (.);

$\mathrm{Pn}=$ Potencia nominal da máquina $(\mathrm{CV})$.

Levando em consideração que a eficiência da máquina se altera para diferentes porcentagens de carregamento, é necessário após descobrir o carregamento de cada motor, reajustar o índice de eficiência da operação, observando a curva de carga do modelo da máquina.

Com relação ao rendimento ou eficiência da operação (n), ela é importante para podermos mensurar o consumo de energia com cada máquina de indução, e para obter o rendimento (ou eficiência), se deve fazer o uso da equação (3).

$$
n(\%)=\frac{\begin{array}{l}
\text { Equação }(3): \\
\mathrm{P} * 0,735 * \mathrm{FC}
\end{array}}{\frac{(\sqrt{3} * V * I * \cos \varphi)}{1000}} x 100
$$

Na qual,

$\mathrm{P}=$ Potencia nominal do motor $(\mathrm{CV})$;

$\mathrm{FC}=$ Fator de carregamento (.);

$\mathrm{V}=$ Tensão elétrica da rede $(\mathrm{V})$;

$\mathrm{I}=$ Corrente $(\mathrm{A})$

$\cos \varphi=$ Fator de potência da rede (.)

A Equação (4) fornece o consumo elétrico da operação de cada máquina.

$$
C=\frac{\begin{array}{c}
\text { Equação (4): } \\
\text { Pn } \times 735,499 \times \mathrm{T} \times \mathrm{FC}
\end{array}}{\frac{\text { ncorrigido }}{100}} \div 1000
$$

Sendo,

$\mathrm{C}$ : Consumo anual da operação da máquina $(\mathrm{kWh})$;

Pn: Potência nominal do motor de indução (CV);

T: Tempo de operação anual das máquinas (h);

ncorrigido: Eficiência corrigida de acordo com o carregamento obtido via cálculo (.).

Para a obtenção da tarifa de consumo (TC) em reais, é essencial realizar o equacionamento da tarifa elétrica da concessionária local, de forma a conseguir uma estimativa do preço pago no quilowatt-hora ( $\mathrm{kWh}$ ). 


$$
\begin{gathered}
\text { Equação (5): } \\
T C=\frac{\mathrm{TH}}{1-\sum \text { tributos }}
\end{gathered}
$$

Com,

TH: tarifa horária da concessionária local (R \$MWh).

Todos os valores foram obtidos com base em dados de placa, valores medidos durante o processo produtivo da planta motriz e documentos enviados pela própria empresa.

Etapa 2: Conhecer o comportamento dinâmico das máquinas, compreendendo os processos de partida das máquinas, porque muitas vezes o sobredimensionamento do motor é necessário para possibilitar a partida de cargas de alta inércia.

Etapa 3: Identificação das máquinas ineficientes e pesquisa por novas máquinas de alta eficiência para substituição adequada (que atenda as condições de carga e durante a partida) dos antigos motores declarados como potencialmente ineficientes.

Etapa 4: Comparação entre a operação dos motores antigos e atuais e levantamento de custos, assim como a quantidade de energia anual a ser economizada com a implementação do projeto e também o tempo de retorno do investimento, utilizando ferramentas estatísticas e matemáticas.

Nesta etapa, levou-se em consideração o tempo da vida útil dos motores de indução em operação na indústria, pois dependendo do tempo de vida útil remanescente, a economia energética e financeira que uma troca de máquina possibilitaria, pode não ser suficiente para justificar a troca antes do término da vida útil da máquina em questão.

\section{Resultados e Discussão}

\section{a) Definição das Máquinas Ineficientes}

Após a definição da metodologia a ser utilizada, foram coletados os dados remanescentes juntamente a empresa, sendo esses dados, valores de placa das máquinas e medições de corrente durante a operação dos motores, para ser possível estimar seu carregamento. A partir do equacionamento foi possível obter valores de interesse ao projeto e realizar seu tabelamento para um melhor controle das variáveis.

A seguir foram estimadas a eficiência média de cada faixa de potência das máquinas de indução (de 5 até $300 \mathrm{CV}$ ), demonstrados na Figura 4, para uma melhor visualização analítica, a partir de dados obtidos da empresa analisada, destinados para o estudo em questão. 
Figura 4: Eficiência/Rendimento médio das faixas de potência referentes às máquinas analisadas.

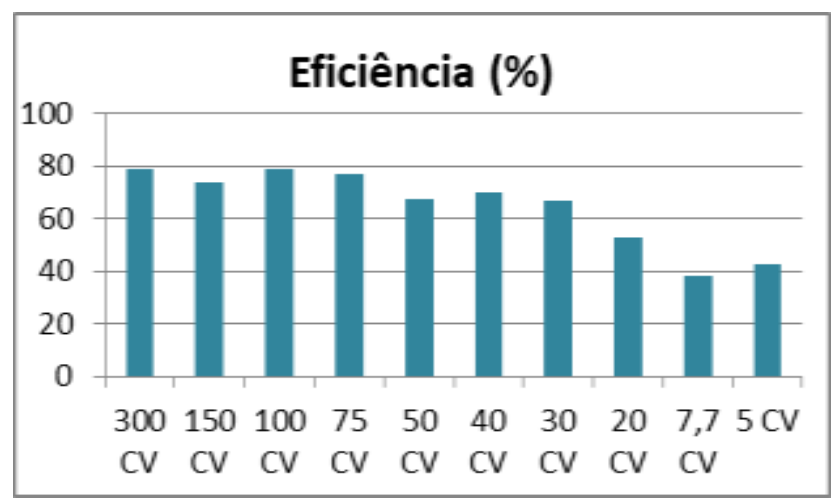

Fonte: Autores.

Estes dados são importantes para uma noção do atual estado produtivo da maior parte da planta motriz que compõe a empresa.

O seguinte Diagrama de Sankey, apresentado na Figura 5, revela em quais máquinas se encontram os maiores consumos de energia anual (em kWh), e são relevantes para o cálculo do consumo de energia antes e após a implementação da medida de eficiência energética (troca dos motores), assim como possibilita uma maior transparência para o estudo em questão.

Figura 5: Diagrama de Sankey do Consumo Elétrico Anual das Máquinas de Indução Trifásicas (em kWh).

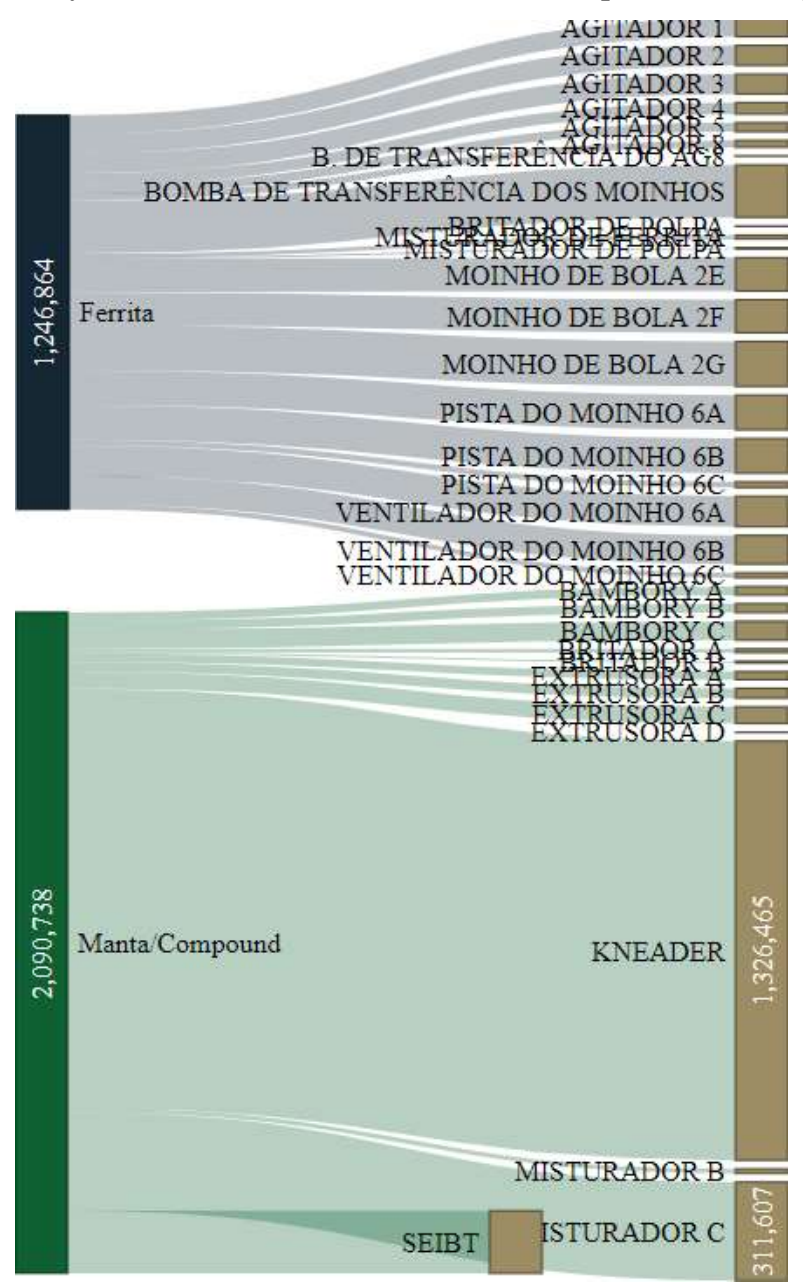

Fonte: Autores. 
Pela Figura 5 é possível notar quais máquinas são responsáveis pelo maior consumo de energia anual da empresa e então traçar uma relação se esse consumo se deve ao tempo de operação anual da máquina e sua potência ou então a um mau dimensionamento e baixo carregamento do respectivo motor.

Somando o consumo de energia das máquinas pertencentes aos dois galpões produtivos da empresa, o consumo de energia anual em reais, levando em consideração o valor da tarifa de energia e horas trabalhadas, valores estes demonstrados anteriormente, o gasto com energia anual em reais foi de $\mathrm{R} \$ 971.888,77$.

Avaliou-se que os motores da empresa operam foram das condições nominais. As Figuras 6 e 7 apresentam os fatores de carregamento calculados de cada motor de indução dos dois galpões produtivos da empresa.

Figura 6: Fator de Carregamento das máquinas do Galpão de Manta Magnética e Compound.

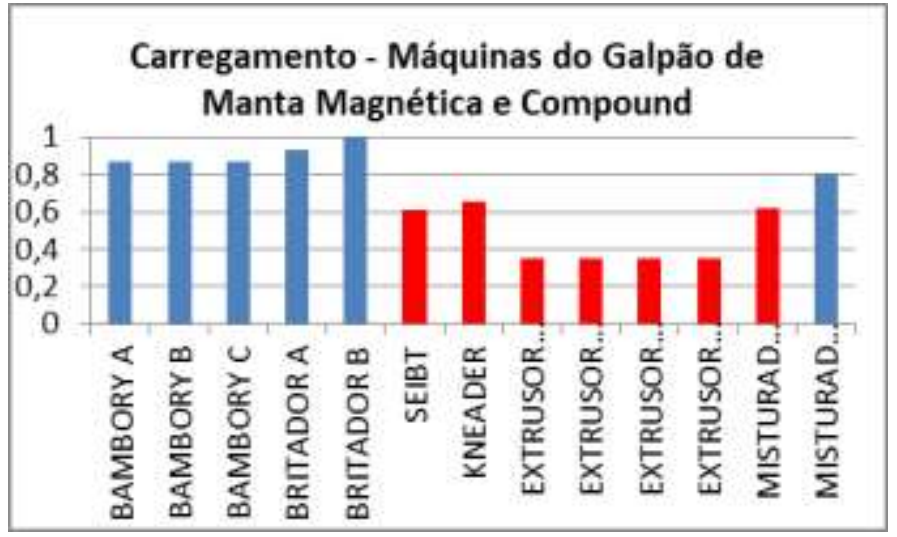

Fonte: Autores.

Figura 7: Fator de Carregamento das máquinas do Galpão de Ferrita.

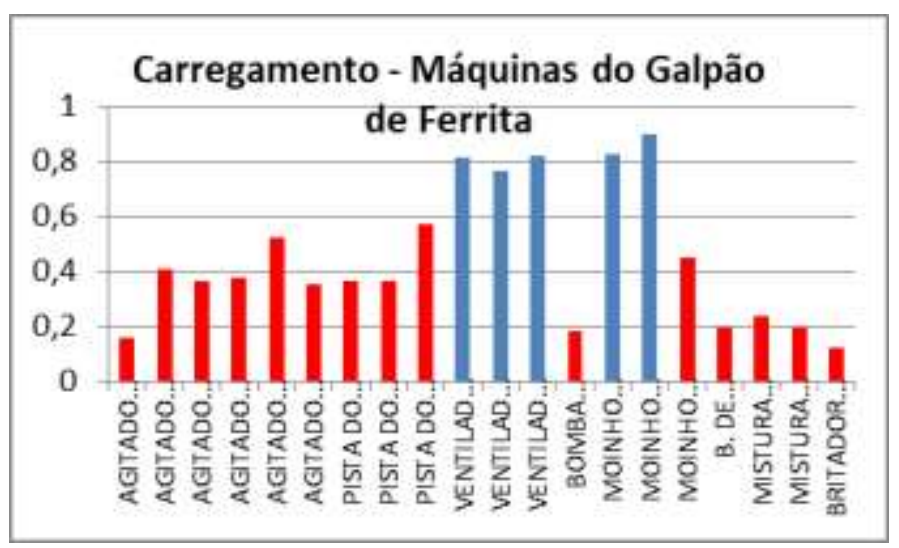

Fonte: Autores.

A partir das análises das Figuras 6 e 7 foi possível notar algumas colunas em vermelho. Isso se deve às máquinas que obtiveram um Fator de Carregamento inferior à 70\%, uma porcentagem em que já ocorrem perdas significativas na eficiência motriz devido ao baixo carregamento.

Alguns equipamentos, como é o caso da máquina SEIBT, de $75 \mathrm{CV}$, possui um baixo fator de carregamento de 0,61 e uma considerável quantidade de horas de trabalho anual, aproximadamente 2.844 horas, o que justifica seu alto consumo de 197.510,8 kWh, que poderia ser reduzido caso a máquina estivesse bem dimensionada para a carga com a qual trabalha. Quanto ao restante dos equipamentos com consumos consideráveis e carregamento abaixo do ideal, é possível observar, em termos gerais, que se encontram nas máquinas de menor potência. 
Em seguida foi feita uma análise dos índices de rendimento, ou eficiência, os quais foram obtidos com base nos carregamentos anteriormente demonstrados, apresentados nas Figuras 8 e 9.

Figura 8: Rendimento das máquinas do Galpão de Manta Magnética e Compound.

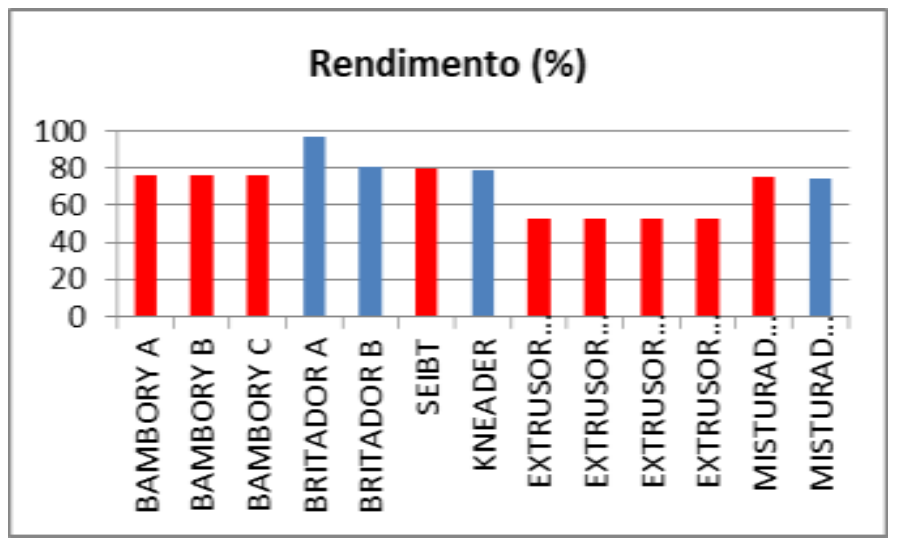

Fonte: Autores.

Figura 9: Rendimento das máquinas do Galpão de Ferrita

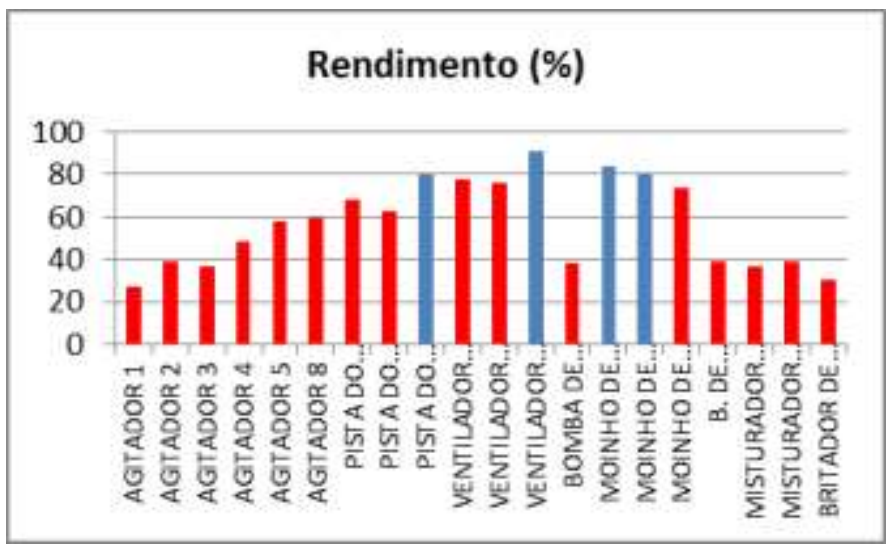

Fonte: Autores.

Com exceção de algumas máquinas que possuem um bom aspecto construtivo e são intrinsicamente eficientes ou que são máquinas de alta potência e não possuem uma curva de eficiência de alta sensibilidade para o carregamento, diversas máquinas mostraram valores de eficiência indesejados devido ao baixo fator de carregamento obtido, principalmente no Galpão de Ferrita. Entretanto, também se verifica uma boa parte do maquinário do Galpão de Manta Magnética e Compound com índices de rendimento abaixo de $80 \%$.

Com os resultantes das análises da planta motriz apresentados, o próximo capítulo avalia os resultados energéticos e econômicos de substituição de máquinas motrizes para a empresa.

Os itens: b) e c) seguintes apresenta os estudos das possibilidades de substituição de motores elétricos, com seus gastos energéticos e financeiros anuais, bem como as análises de viabilidade econômica para a troca por motores elétricos com maiores desempenhos energéticos.

\section{b) Substituição da Planta Motriz por Máquinas de Alta Eficiência}

Para o estudo de substituição da planta motriz, foi realizada uma consulta a uma empresa representante da fabricante WEG do estado de São Paulo, na qual foi obtido o valor de R \$ 536.384,00 para a compra de todas as máquinas dos galpões 
produtivos analisados, sendo essas máquinas adequadas aos seus respectivos tipos de carga e corrente de operação e todas pertencentes à linha Super Premium, que é uma linha de alta eficiência.

A Tabela 3 mostra as taxas de eficiência esperadas dos motores de indução de alto desempenho assim como seu gasto anual com energia projetado, calculado para o mesmo tempo de operação dos outros motores antigos.

Tabela 3: Eficiência dos motores de alto desempenho, consumo energético e gasto anual projetado.

\begin{tabular}{|c|c|c|c|}
\hline Máquinas & $\begin{array}{l}\text { Nova Eficiência } \\
\text { Projetada }(\%)\end{array}$ & $\begin{array}{l}\text { Consumo Anual } \\
\text { de Energia } \\
\text { Projetado (kWh) }\end{array}$ & $\begin{array}{l}\text { Gasto Anual } \\
\text { Projetado com } \\
\text { Operação (R\$) }\end{array}$ \\
\hline MÁQUINA 1 & 0,945 & $21.714,73$ & $6.323,19$ \\
\hline MÁQUINA 2 & 0,945 & $22.570,87$ & $6.572,49$ \\
\hline MÁQUINA 3 & 0,945 & $48.488,45$ & $14.119,52$ \\
\hline MÁQUINA 4 & 0,924 & $12.258,32$ & $3.569,54$ \\
\hline MÁQUINA 5 & 0,92 & $4.460,96$ & $1.299,00$ \\
\hline MÁQUINA 6 & 0,936 & $167.608,91$ & $48.806,64$ \\
\hline MÁQUINA 7 & 0,953 & $1.101 .627,78$ & $320.787,01$ \\
\hline MÁQUINA 8 & 0,92 & $16.659,05$ & $4.851,01$ \\
\hline MÁQUINA 9 & 0,913 & $18.077,32$ & $5.264,00$ \\
\hline MÁQUINA 10 & 0,913 & $30.547,78$ & $8.895,31$ \\
\hline MÁQUINA 11 & 0,913 & 386,68 & 112,59 \\
\hline MÁQUINA 12 & 0,93 & $11.427,91$ & $3.327,73$ \\
\hline MÁQUINA 13 & 0,945 & $244.640,98$ & $71.237,90$ \\
\hline MÁQUINA 14 & 0,861 & $18.336,22$ & $5.339,39$ \\
\hline MÁQUINA 15 & 0,902 & $27.532,29$ & $8.017,22$ \\
\hline MÁQUINA 16 & 0,861 & $26.697,08$ & $7.774,01$ \\
\hline MÁQUINA 17 & 0,861 & $20.347,95$ & $5.925,19$ \\
\hline MÁQUINA 18 & 0,861 & $18.964,09$ & $5.522,22$ \\
\hline MÁQUINA 19 & 0,93 & $13.800,49$ & $4.018,61$ \\
\hline MÁQUINA 20 & 0,92 & $81.000,82$ & $23.586,92$ \\
\hline MÁQUINA 21 & 0,92 & $75.052,88$ & $21.854,92$ \\
\hline MÁQUINA 22 & 0,92 & $15.637,35$ & $4.553,49$ \\
\hline MÁQUINA 23 & 0,924 & $80.650,17$ & $23.484,81$ \\
\hline MÁQUINA 24 & 0,924 & $74.727,97$ & $21.760,31$ \\
\hline MÁQUINA 25 & 0,92 & $15.637,35$ & $4.553,49$ \\
\hline MÁQUINA 26 & 0,924 & $68.837,61$ & $20.045,07$ \\
\hline MÁQUINA 27 & 0,945 & $93.163,21$ & $27.128,53$ \\
\hline MÁQUINA 28 & 0,945 & $89.038,19$ & $25.927,35$ \\
\hline MÁQUINA 29 & 0,945 & $110.558,34$ & $32.193,88$ \\
\hline MÁQUINA 30 & 0,92 & 415,72 & 121,05 \\
\hline MÁQUINA 31 & 0,861 & $1.704,21$ & 496,25 \\
\hline MÁQUINA 32 & 0,913 & $5.300,75$ & $1.543,54$ \\
\hline MÁQUINA 33 & 0,92 & 335,77 & 97,77 \\
\hline TOTAL: & & $2.538 .208,19$ & 739.109,9494 \\
\hline
\end{tabular}

Fonte: Autores.

Se as máquinas forem bem dimensionadas para a carga que irão atuar, essa deve ser a faixa de eficiência mínima esperada em regime permanente de operação. Com esses índices de rendimento o consumo total anual sofre uma queda de valor agregado anualmente de $\mathrm{R} \$ 971.888,77$ reais para o valor total de $\mathrm{R} \$ 739.109,94$ reais, ou seja, uma redução do gasto anual de $\mathrm{R} \$ 232.778,83$ reais, ou, $23,95 \%$. 
Porém, apesar de a maioria das máquinas ter apresentado valores baixos ou críticos de carregamento, apenas deverão ser substituídos os motores declarados sobre dimensionados, ou seja, as máquinas que apresentaram menos de $70 \%$ de carregamento. Máquinas essas apresentadas em destaque na Tabela 4 seguinte.

Tabela 4: Novos gastos anuais projetados, consumo energético e rendimento das máquinas a serem substituídas.

\begin{tabular}{|c|c|c|c|}
\hline Máquinas & $\begin{array}{l}\text { Nova Eficiência } \\
\text { Projetada }(\%)\end{array}$ & $\begin{array}{l}\text { Consumo Anual } \\
\text { de Energia } \\
\text { Projetado }(k W h)\end{array}$ & $\begin{array}{l}\text { Gasto Anual } \\
\text { Projetado com } \\
\text { Operação (R\$) } \\
\end{array}$ \\
\hline MÁQUINA 1 & 0,763665849 & $26.870,94$ & $7.824,65$ \\
\hline MÁQUINA 2 & 0,764221809 & $27.910,05$ & $8.127,23$ \\
\hline MÁQUINA 3 & 0,764773116 & $59.915,27$ & $17.446,95$ \\
\hline MÁQUINA 4 & 0,965211266 & $11.734,93$ & $3.417,14$ \\
\hline MÁQUINA 5 & 0,809215194 & $5.071,68$ & $1.476,84$ \\
\hline MÁQUINA 6 & 0,936 & $167.608,91$ & $48.806,64$ \\
\hline MÁQUINA 7 & 0,953 & $1.101 .627,78$ & $320.787,01$ \\
\hline MÁQUINA 8 & 0,92 & $16.659,05$ & $4.851,01$ \\
\hline MÁQUINA 9 & 0,913 & $18.077,32$ & $5.264,00$ \\
\hline MÁQUINA 10 & 0,913 & $30.547,78$ & $8.895,31$ \\
\hline MÁQUINA 11 & 0,913 & 386,68 & 112,59 \\
\hline MÁQUINA 12 & 0,93 & $11.427,91$ & $3.327,73$ \\
\hline MÁQUINA 13 & 0,7419 & $311.606,52$ & $90.737,84$ \\
\hline MÁQUINA 14 & 0,861 & $18.336,22$ & $5.339,39$ \\
\hline MÁQUINA 15 & 0,902 & $27.532,29$ & $8.017,22$ \\
\hline MÁQUINA 16 & 0,861 & $26.697,08$ & $7.774,01$ \\
\hline MÁQUINA 17 & 0,861 & $20.347,95$ & $5.925,19$ \\
\hline MÁQUINA 18 & 0,861 & $18.964,09$ & $5.522,22$ \\
\hline MÁQUINA 19 & 0,93 & $13.800,49$ & $4.018,61$ \\
\hline MÁQUINA 20 & 0,92 & $81.000,82$ & $23.586,92$ \\
\hline MÁQUINA 21 & 0,92 & $75.052,88$ & $21.854,92$ \\
\hline MÁQUINA 22 & 0,92 & $15.637,35$ & $4.553,49$ \\
\hline MÁQUINA 23 & 0,7738 & $96.295,86$ & $28.040,74$ \\
\hline MÁQUINA 24 & 0,7607 & $90.760,21$ & $26.428,80$ \\
\hline MÁQUINA 25 & 0,9066 & $15.868,03$ & $4.620,67$ \\
\hline MÁQUINA 26 & 0,924 & $68.837,61$ & $20.045,07$ \\
\hline MÁQUINA 27 & 0,8345 & $105.498,31$ & $30.720,44$ \\
\hline MÁQUINA 28 & 0,8051 & $104.502,09$ & $30.430,34$ \\
\hline MÁQUINA 29 & 0,945 & $110.558,34$ & $32.193,88$ \\
\hline MÁQUINA 30 & 0,92 & 415,72 & 121,05 \\
\hline MÁQUINA 31 & 0,861 & $1.704,21$ & 496,25 \\
\hline MÁQUINA 32 & 0,913 & $5.300,75$ & $1.543,54$ \\
\hline MÁQUINA 33 & 0,92 & 335,77 & 97,77 \\
\hline TOTAL: & & $2.686 .890,89$ & $782.405,50$ \\
\hline
\end{tabular}

Fonte: Autores.

Com esse novo cenário, o novo gasto anual sofre um pequeno acréscimo de $\mathrm{R} \$ 43.295,55$ reais anuais. Isso se deve ao fato de que as máquinas que não se encontram na condição de baixo carregamento não são máquinas de alta eficiência como as máquinas do orçamento realizado, então embora elas não estejam mal dimensionadas, elas ainda consumirão mais energia que uma máquina da linha Super Premium, por exemplo. Entretanto, realizando a substituição apenas do maquinário declarado de fato sobredimensionado, ou ineficiente, temos uma queda no valor do orçamento total de cerca de $50 \%$ se comparado ao valor anterior, ou seja, o novo orçamento calculado obteve o valor de $\mathrm{R} \$ 264.718,00$ (correspondente ao investimento total). Com os custos e valores de economias monetárias calculados foi possível avaliar a viabilidade deste investimento, apresentada a seguir. 


\section{c) Análise Financeira do Projeto}

A análise financeira de um projeto de eficiência é a base para a tomada de decisão de investimento. A análise financeira pode variar em sofisticação a partir de um simples retorno (investimento / economia anual líquida) ou taxa de retorno (economia líquida média anual / investimento total) para cálculos mais precisos, como o valor presente líquido (VPL) ou taxa interna de retorno (TIR), que leva em conta o valor do dinheiro no tempo. Independentemente de qual cálculo é usado, a parte mais importante de uma análise financeira é a estimativa dos custos e benefícios do projeto (Elliot et al., 1997). Diversos critérios econômicos podem ser utilizados para avaliar a viabilidade do projeto e do investimento. Entre eles, analisaremos o VPL, TIR e o Payback.

Primeiramente é necessário definir a TMA (Taxa Mínima de Interesse) da empresa, assim como montar o fluxo de caixa, adotada de 6,25\% a.a. (correspondente a taxa de inflação do ano em estudo). Para a obtenção do valor do Tempo de Retorno, ou Payback, com ganho no período de R\$ 189.483,20 e investimento de R\$264.718,00, e considerando a TMA de 6,25\% a.a., utilizando a equação (6) tem-se o Payback no período de 1,5 anos.

$$
\begin{gathered}
\text { Equação (6): } \\
\text { Payback }=\frac{\text { Investimento }}{\text { Beneficio }}=\frac{\ln \left(1-\frac{\mathrm{I}}{\mathrm{A}} \cdot \mathrm{i}\right)}{\ln (1+\mathrm{i})}
\end{gathered}
$$

Sendo,

I: Investimento (R\$);

A: Economia Anual (R\$);

i: Taxa de juros (\% ao ano).

Com o auxílio do software Excel, foi possível obter de forma simples, através de funções específicas do mesmo, os valores da Taxa Interna de Retorno (TIR) e do Valor Presente Líquido (VPL). Com o auxílio da ferramenta computacional obteve-se a TIR de 70\% a.a. e VPL de R \$ 523.611,66. Tendo em vista que a TIR apresentou valor superior à TMA, e que o valor do VPL foi positivo, é correto afirmar que o projeto é, de fato, viável do ponto de vista econômico para a empresa.

\section{Conclusões}

Após processos de obtenção e análises de dados técnicos, é de total interesse do consumidor e do empresário compreender que, de uma forma geral, a substituição da planta motriz por máquinas de alta eficiência sempre trará benefícios quanto à economia de energia, porém será necessário realizar estudos quanto à viabilidade do investimento levando em consideração as atuais taxas de juros do mercado e a taxa de interesse da própria empresa, com a finalidade de garantir que em prazos de tempo determinados esse investimento seja atrativo para a empresa.

Quanto a este estudo realizado em uma empresa de processamento de produtos ferromagnéticos, localizada em Itabira-MG, os resultados econômicos mostraram que com um investimento de cerca de $\mathrm{R} \$ 264.718,00$ para troca de motores elétricos menos eficientes por mais eficientes, a empresa alcança uma economia monetária anual de $\mathrm{R} \$ 189.483,20$ reais em sua conta de energia elétrica, propiciando TIR de 70\% a.a. e TR de 1,5 anos, demonstrando boa atratividade econômica.

Em termos de gestão, a definição das máquinas ineficientes e com baixo carregamento é de fundamental importância para saber onde focar os recursos da empresa, visto que a substituição dessas máquinas mal dimensionadas é que contribuirão com a parte majoritária da economia na conta de energia elétrica. 
Research, Society and Development, v. 11, n. 2, e0211224878, 2022

(CC BY 4.0) | ISSN 2525-3409 | DOI: http://dx.doi.org/10.33448/rsd-v11i2.24878

\section{Referências}

Bortoni, E. C., Nogueira, L. A. H, Cardoso, R. B, \& Haddad, J. (2013). Assessment of the achieved savings from induction motors energy efficiency labeling in Brazil, Energy Conversion and Management.

Bortoni, E. C. (2009). Are my motors oversized? Energy Conversion and Management.

Brasil, Ministério das Minas e Energia - MME. (2007). Plano Nacional de Energia 2030. Eficiência Energética (11). MME/EPE.

Cardoso, R. B., (2015). Etiquetagem e Eficiência Energética. Appris, 143 p.

Cardoso, R. B., Nogueira, L. A. H., Haddad, J., \& Bortoni, E. C. (2009). Avaliação da economia de energia, atribuída a ações de etiquetagem energética, em motores de indução no Brasil. Revista Brasileira de Energia, 15, 29-47.

De Keulenaer, H., Belmans, R., Blaustein, E., Chapman, D., De Almeida, A., \& De Wachter B. (2004). Energy efficient motor driven systems.

Elliot, R, N., Laitner, S., \& Pye, M. (1997). Considerations in the Estimation of Costs and Benefits of Industrial Energy Effiency Projects.

Fonseca, J. P. S. M., Ferrari, E. M. M., \& Cardoso, R. B. (2018). Análise dos impactos energéticos e econômicos do programa brasileiro de etiquetagem energética (PBE/Inmetro) em coletores solares térmicos do Brasil. Research, Society and Development, 7, 107.

Sankey Diagram Generator. (2021). Acquire Procurement Services. <http://sankey-diagram-generator.acquireprocure.com/>.

Nogueira, L. A. H, Cardoso, R. B. C, Cavalcante, C., \& Leonelli, P. A. (2015). Evaluation of the energy impacts of the Energy Efficiency Law in Brazil. Energy Sustainable Development, 24, 58-69.

Santos, A. H. M. et al. (2007). Eficiência Energética, Teoria e Prática. Eletrobrás /Procel Educação. Universidade Federal de Itajubá.

Sola, A. V. H. \& Mota, C. M. M. (2015). Melhoria da Eficiência Energética em Sistemas Motrizes Industriais.

World Energy Council - WEC. (2010). Energy efficiency: a recipe for success.

Worrel et al. (2009). Industrial Energy Efficiency and Climate Change Mitigation.

Xenergy, Inc. (1998) Evaluation of the US Department of Energy Motor Challenge Program. 